\title{
Culture du virus de la Rhinotrachéite infectieuse des bovins sur les cellules testiculaires d'embryon de mouton
}

\author{
par NGUYEN BA-VY ef P. PERREAU
}

\begin{abstract}
RÉSUMÉ
La multiplication du'virus de la rhınotrachéite infectieuse bovine peut s'effectuer sur des celfules testiculaires d'embryon de mouton, cultivées in vitro en milieu à base d'hydrolysat de lactalbumine additionné de sérum d'agneau et de veau. Elle se manifeste par un effet cytopathogène au bout de vingt à quarante heures d'incubation à $37^{\circ} \mathrm{C}$. De grosses inclusions éosınophiles d'un type particulier ont été observées dans le cyloplasme d'un certain nombre de cellules atteintes. Les cellules séroprotégées restent normales.
\end{abstract}

La rhinotrachéite infectieuse bovine est une maladie virale, contagieuse, inoculable, caráctérisée par de la fièvre, de l'inflammation exsudative des premieres voies respiratoires el de la dyspnée. Cette maladie, très répandue en Amérique du Nord, a été observée en Allemagne, en Nouvelle-Zélande et en Angleterre. En Afrique centrale plusieurs foyers ont été observés dans la région du lac du Tchad et les souches de virus isolées et identifiées par PROVOST et BORREDON (1). Nous avons des raisons de craire qu'elle existe aussi en Afrique occidentale, puisque dessérums de bovins de Côte-d'lvoire se sont révélés, entre nos mains, très positifs au test de séroneutralisation en culture cellulaıre. Dans les régions où sévit la peste bovine, un risque de confusion existe, tout au moins au début de l'évolution clinique, puisque l'hyperthermie et le jetage, nasal sont des signes communs à ces deux affections.

Le virus a été isolé en 1956 et cultivé sur celIules rénales d'embryon de bovin par MADIN. YORK et MC KERCHER (2). La culture a été effectuée aussi sur cellules rénales de bovin (SCHWARZ et coll. 1957) (3), sur cellules cancéreuses de souche Hela (CABASSO et coll. 1957) (4) (ORSI et CABASSO, 1958) (5), sur cellules rénales de porc (SCHWARZ et coll. 1958) (6), sur cellules de l'amnios humain (CHEATHAM et CRANDELL 1957) (7), sur cellules rénales de chien (GILLESPIE, 1959, cité par MADIN) (8) Selon MC KERCHER (9) la multiplication virale avec effet cytopathogène peut se faire aussi sur cellules rénales de caprin, d'ovın, d'équin, sur cellules testiculaires de lapın, et sur cellules de ganglions lymphatrques de bovin. Ce virus ne se multiplie pas sur fibroblastes d'embryon de poulet, sur cerveau de souris ou sur cellules rénales de cobaye, de souris et de singe (MADIN 1958, cité par Mc KERCHER) (9). En 1961, KNOCKE et LIESS (10) ont cultivé ce virus sur cellules testiculaires et rénales de bovin et ont observé des corpuscules intranucléaires et intracytoplasmiques à l'examen au microscope électronique.

Dans ce travail, nous présentons les résultats obtenus sur des cellules testiculaires de fœetus de mouton, dont l'intérêt, nous semble-t-il, est d'avoir permis l'observation d'inclusions intracellulaires particulières.

\section{MATÉRIEL ET TECHNIQUES}

\section{1. - Milieux de culture}

Le milieu à base d'hydrolysat de lactalbumıne (Difco) (à 0,5 p. 100 en solution de Hanks) est additionné de 0,5 p. 100 d'extrait de levure (Yeast Extract, Difco) de 5 p. 100 de sérum de veau et de 5 p. 100 de sérum dé. mouton "Les 
antibiotıques sont ajoutés à raison de $100 \mathrm{U}$.de pénicilline, de $100 \mu \mathrm{g}$ de streptomycine et de 100 U. de Mycostatine par $\mathrm{ml}$ de milieu.

Ce milieu convient pour la croissance des cellules de première explantation et pour les premiers passages. Pour les passages ultérieurs (à partir du $3 \mathrm{e}$ ) il faut remplacer le sérum de mouton adulte par du sérum, d'agneau (*). HESS et ses collaborateurs (11) ont préconisé le milieu d'Eagle-Hanks additionné de 10 p. 100 de sérum d'agneau pour la croissance des cellules testiculaires.

Le milieu d'entretien contient seulement 5 p. 100 de sérum d'agneau.

\section{2. - Solution de trypsine}

C'est la trypsine Difco (1/250) à 0,25 p. 100 en solution de Hanks. Le pH estajusté à 7,5 avec une solution de bicarbonate de sodium à 1,4 p. 100.

\section{3. - Trýpsination des testicules embryonnaires de móuton}

Les testicules prélèvés aseptiquement sont débarrassés de la vaginale et'de l'épididyme, puis lavés ávec de la solution de Hariks. On incise erisuite l'albuginée dans le sens du grand axe et on sépare le tissu seminifère qui serd découpé finement en petits ifragiments. Après 3 lavagès avec du Hariks, ces morceaux sont mis en suspension dahs $50 \mathrm{ml}$ de trypsine pendant $10 \mathrm{mi}-$ nute's à la température du laboratoire. L'e surnageant est jeté è remiplacé por $60 \mathrm{ml}$ de trypsine neuve. La suspension est agitée très doucement peridant deux heures à $370 \mathrm{C}$.

On sépare par décantation la suspensión celfulaire de gros fragments tissulaires qui peuvent être sourris à une nouvelle trypsination. Après une centrifugation à $1.000 \mathrm{t} / \mathrm{m}$ pendant 5 minutes, le culot cellulaire est dosé, remis en suspension dans $20 \mathrm{ml}$ de milieu nutritif et soumis à un pipettage vigoureux. On ajoute du milieu de culture en quantité suffisante pour avoir une suspension de cellules à 0,5 p. $100(\mathrm{v} / \mathrm{v})$ avant la distribution en flacons.

(*) Dans ce travall, nous avons utilisé le sérum d'agneaux de boucherie âgés de 4 à 6 mois ; dans la proportion de 10 p. $100(\dot{v} / \mathrm{v})$.
Les cellules de première explantation forment une nappe rugueuse et tourmentée. A partir du deuxième passage, elles sont plus régulières, constituant un tapis lisse et continu.

\section{4. - Souches de virus}

Les deux souches de virus de rhınotrachéite Infectieuse bovine ( $L$. A. E.) et $\left(B_{1}\right) 45$, nous ontété envoyées par le laboratore de Farcha (Tchad) (*) La première provient du Veterinary Virus Research Institute (Cornell University, Ithaca New York) et a été passée 5 fois sur cellules rénales d'embryon de bovin. La deuxième provient de la collection du Professeur WAGNER, de I'Ecole vétérinaire de Hanovre en Allemagne.

\section{5. - Antisérums}

Les lapins reçoivent par voie intra-veıneuse $1 \mathrm{ml}$ de culture de virus, 2 fois par semaine et pendant 3 semaines. On vérifie au bout de la 4 e semaine le titre du sérum obtenu par panction cardiaque. S'il est satisfasant ; on saigne les animaux 10 jours après la dernière injection.

Deux antisérums de bovins convalescents nous ont été envoyés du Tchad.

\section{6. - Titrage du virus}

La suspenision virulente est diluée selon une progression décimale dé $10^{-1}$ à $10^{-8}$, dvec du milieu d'entrefient. Les tubes de cellules sont vidés de lieur ancien milieu. Oín y djoute $0,2 \mathrm{ml}$ de chaque dilution viralè ( 5 tubes pour chacune) en commençant par la plus forte dilution qui est en général 10-8 pour ter'miner à 10-3.

Après une incubafion à $370 \mathrm{C}$ pendant 1 heure, chaque tube' reçoit $1 \mathrm{mil}$ de milieú d'éritrétien. "ainśi que les 5 túbes tẻmoins. La lécture sé fait au 4 e et 5 jour d'incubation à 370 , par la rechèrchè du pouvoir cytopathogène. La dóse infectante 50 p. $100\left(\mathrm{DICT}_{50}\right)$ est calculée selon la méthode de REED et MUENCH.

\section{7. - Tesit dé séro-theutralisation}

L'antisérum est dilué à $1 / 2,1 / 10,1 / 20,1 / 40$, etc..., avec du milieu d'entretien et mélangé d̀

(*) Nous tenons à exprimer nos vifs remerciements à notre confrère $A$. Provost qui nous a fourni ces souches: elles sont utilisées au laboratoire de Farcha comme souches de référencen. 
égales parties avec une suspension virulente contenant $100 \mathrm{DICT}_{50}{ }^{1}$ par $0,1 \mathrm{ml}$. Après une incubation à $25^{\circ} \mathrm{C}$ pendant 1 heure, on distribue $0,2 \mathrm{ml}$ de ce mélange par tube de cellules préalablement vidé de l'ancien milıeu, 5 tubes pour chaque dilution sérique. Un lot témoin est infecté avec $100 \mathrm{DICT}_{50}$ par tube. Un autre lot ne reçoit que du milieu d'entretıen. Une nouvelle incubation à $37^{\circ} \mathrm{C}$ pendant 1 heure précède la distribution de $1 \mathrm{ml}$ de milieu d'entretien à tous les tubes. La lecture se fait au $4^{e}$ et au $5^{e}$ jour d'incubation à $37^{\circ} \mathrm{C}$.

\section{RÉSULTATS}

La culture des cellules testiculaires normales montre au moins deux sortes de cellules; les premières qui sont les plus nombreuses sont de taille moyenne $(7 \mu \times 18 \mu)$ avec un noyau ovalaire bombé ou allongé, les secondes ont un noyau énorme (diamètrè de 25 à $32 \mu$ ) et un immense cytoplasme $(40 \times 96 \mu)$. Par la méthode de clonage, on peut isoler ces dernières, qui ne possèdent pas plusieurs noyaux comme les celJules géantes.

La multiplication du virus de la rhinotrachéite infectieuse bovine est positive sur les cellules testiculaires de fotus de mouton. L'effet cytopathogène, qui débute aux environs de la vingtième heure, est très visible au bout de quarante heures d'incubation à $370 \mathrm{C}$. L'inténsité et la netteté de l'infection dépendent de la concentration initiale de virus. La souche RIB $\left(B_{1}\right) 45$ pousse un peu moins rapidement que la souche RIB (LAE). Mais au bout de quelques passages, elle s'adapte aussi bien que la seconde à ces cellules.

L'effet cytopathogène est visible macroscopiquement ; il se manifeste par la perte de l'aspect transparent et uni du tapis cellulaire qui prend un aspect plus ou moins granuleux. Si les cellules n'ont reçu qu'une faible dose de virus, la multiplication de celui-ci se révèle par l'apparition de petites tâches blanchâtres farineuses qui s'agrandissent rapidement pour devenir confluentes.

A l'examen microscopique, on observe une dislocation du tapis cellulaire avec des lacunes et des déchirures plus ou mons grandes et plus ou moins nombreuses selon la sévérité de I'infection. Les cellules se rétractent et s'arron- dissent, les unes complètement tout en conservant un contour net, les autrés gardant avec leurs voisines des connexions faites de minces filaments cytoplasmiques, d'oùil'apparition de chapelets et de grappes cellulaires. Ces cellules sont plus réfringentes que les normales et de plus en plus granuleuses. Il existe parfols d'énormes cellules arrondies provenant des cellules normales de grande tarlle. A un stade plus avancé, la couche cellulaire se détache par lambeaux, entièrement ou en partie. Des cellules isolées ou en grappes flottent librement dans le milieu lıquide au 4 jour. La dégénérescence s'accentue et bientôt It n'en reste plus que des vestiges informes. (voir figures no 1 et $n^{0} 2$ ).

Après coloration à l'hémalun-éosine, les cellules atteintes présentent des noyaux pycnotiques, déformés et fortement basophıles. Certains, en se rétractant, sont séparés du cytoplasme par une aréole claire et offrent ainsi l'aspect d'une inclusion nucléaire. D'autres présentent des images de margination de la chromatine ou de caryorexie. Le cytoplasme, plus ou moıns granuleux, devient une masse réfringente lorsqu'il se rétracte complètement. Sur un certain nombre de cellules qui ont encore leur cytoplasme presque intact ou à peine rétracté, on voit apparaître des inclusions d'un type particulier, sorte d'amas arrondis, granuleux, très éosinophiles et qui se placent au hasard ou en couronne tout autour du noyau (voir figures no 3 , 4 et 5). II n'existe pas d'aréole autour de ces éléments qui ne sont pas aperçus sur les cellules des lots témoins non infectés ou séro-protégés. Par contre on constate sur certaines cellules des inclusions intracytoplasmiques avec une aréole bien nette, mais qui sont peu éosinophiles et existent aussi bien dans les lots infectés que dans les témoins.

Au bout de 72 heures d'incubation à 370 , les cultures de souches $\left(B_{1}\right) 45$ et LAE sur cellules testiculaires ont donné respectivement $10^{6,6}$ $\mathrm{DICT}_{50}$ ef $10^{6,3} \mathrm{DICT}_{50}$ par ml. Il $y$ a de faibles variations de titre selon les souches de cellules utilisées.

La réaction de séroneutralisation montre que les antisérums de lapins et de bovins protègent les cellules contre $1.000 \mathrm{DICT}_{\mathbf{5 0}}$ au minimum. Il existe une séroneutralisation croisée entre nos deux sauches de virus. Les sérums de lapins 


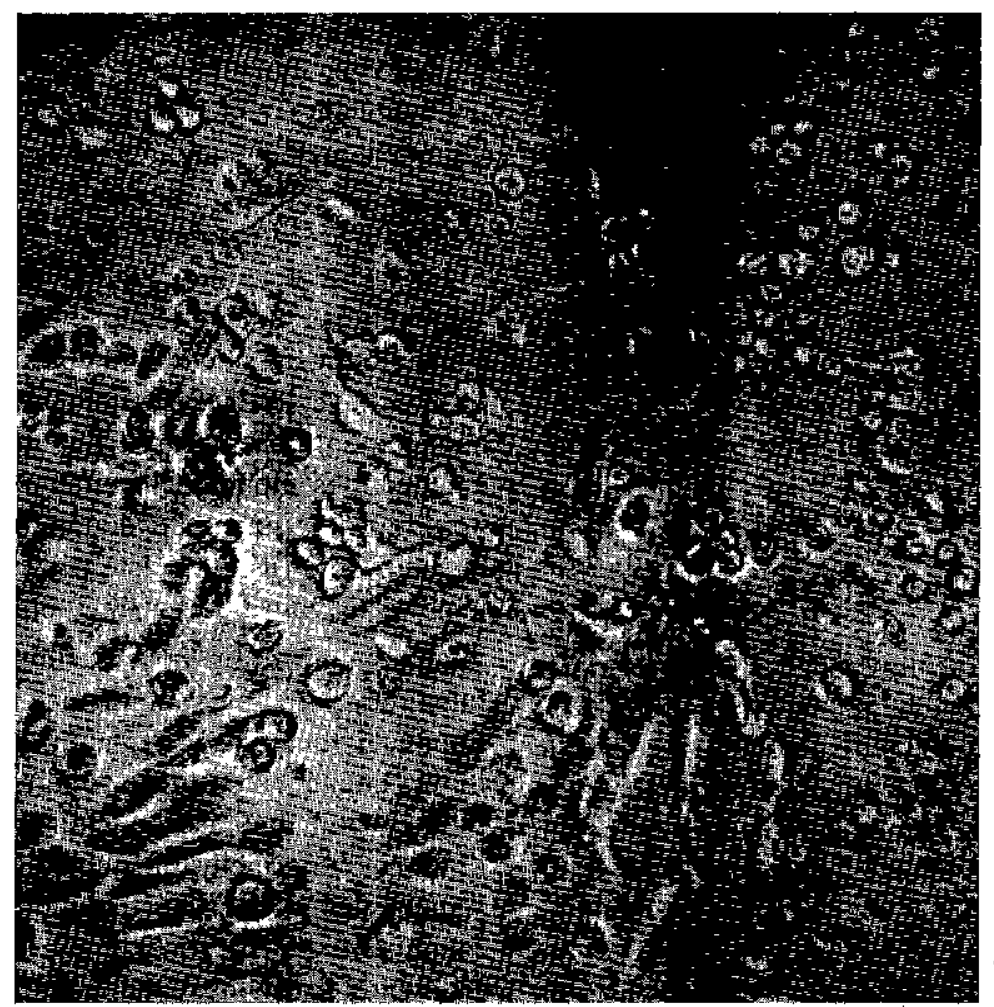

Fig. 1. - Cellules testiculaires ovines infectées par virus RIB (sans coloration Microscope Zeiss, obj. 10/0,22, ocul Kpi $8 \times$

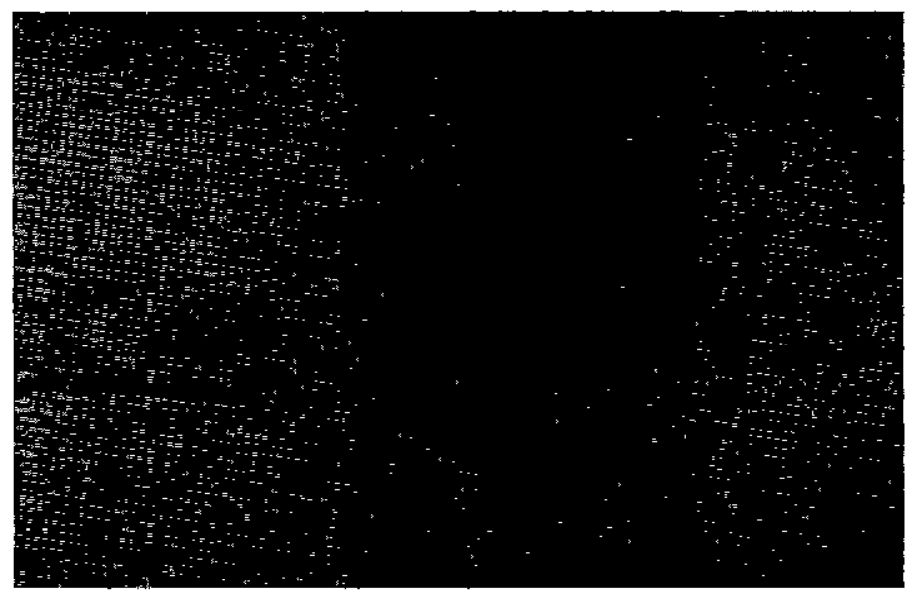

Fig. 2. - Cellule testiculaire ovine infectée par virus RIB ; cytoplasme rétracté et noyau pycnotique (hémalun-éosine) Microscope Zeiss, obj. Plan 100/1,25, ocul. Kpl B. $\times$ 


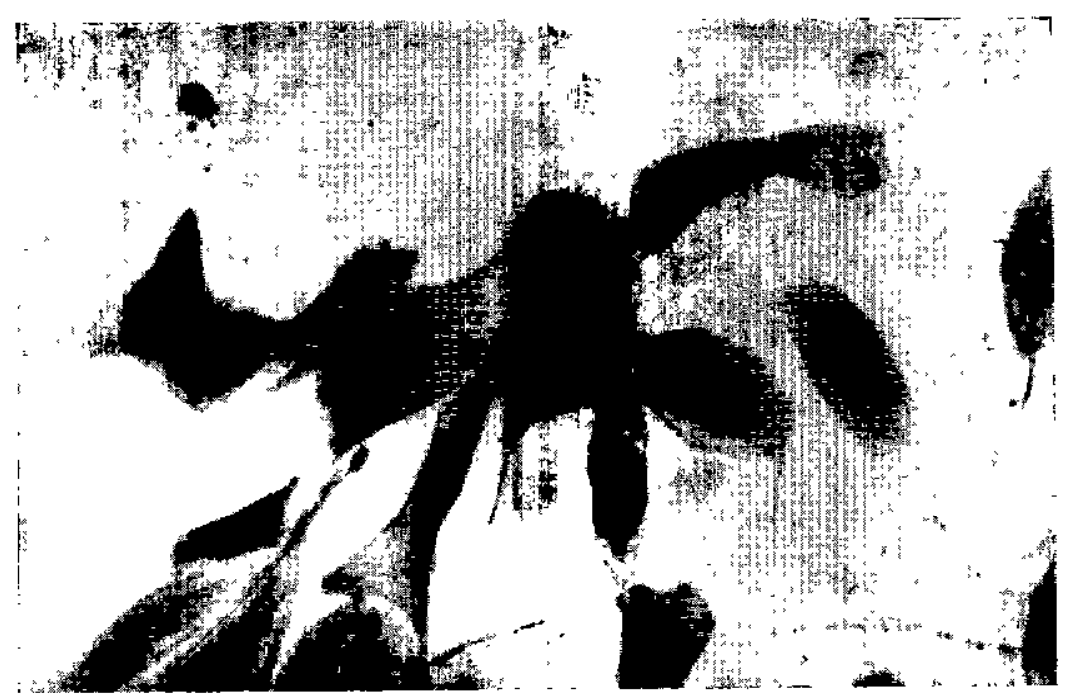

Fig. 3. - Cellules resticulaires ovines infectées par virus RIB ; noyau pycnotique et inclusions intracytoplasmiques (hémalun-éosine) Microscope Zeiss, obj. Neofluar 16/0,40, ocul.' Kpl. $8 \times$

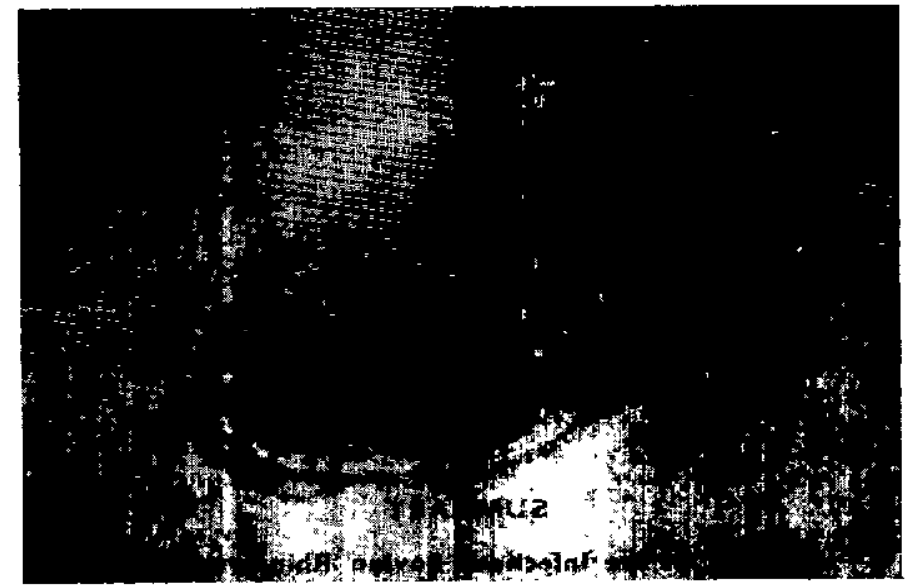

Fig. 4. - Cellule festiculaire ovine infectée par virus RIB : noyau pycnotique, inclusions intracyloplasmiques (hémalun-éosine) Microscope Zeiss, obj. Plan 100/1,25, ocul. Kpl $8 \times$ 


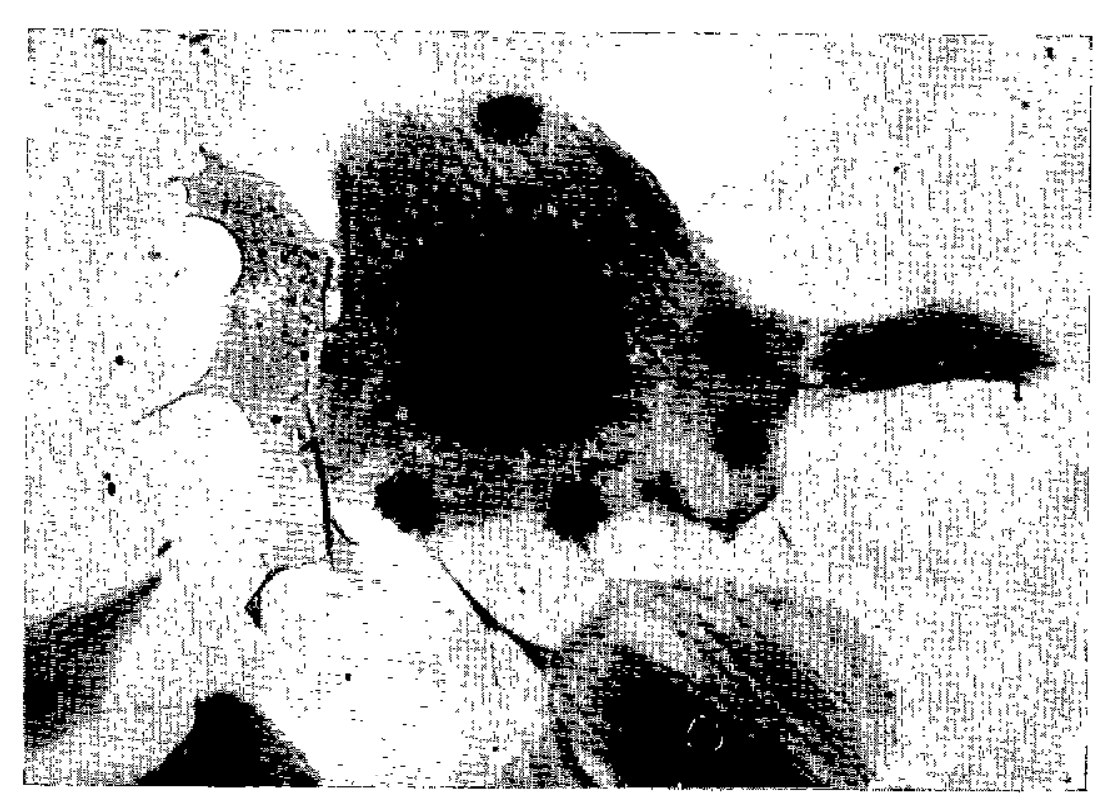

Fig. 5. - Cellule testiculaire ovine infectée par virus RIB ; inclusions intracytoplasmiques (hémalun-éosine) Microscope Zeiss, obj. Néofluar 40/0,75, ocul. Kpl $8 \times$

inoculés avec une culture de cellules normales et les sérums de bovins normaux n'ont aucun pouvoir protecteur vis-à-vis de ce virus.

\section{COMMENTAIRES}

La possibilité de cultiver le virus de la rhinotrachéite infectieuse bovine sur des cellules testiculaires d'embryon de mouton nous offre une nouvelle source de tissu dont la facilité de trypsination, le haut rendement en cellules, le risque réduit de présence de germes saprophytes au niveau de cetorgane (par rapport au rein) nous incitent à ne pas la négliger. Sur les cellules testiculaires d'agneau, PRYDIE ef COAKLEY (11) ont réussi à cultiver le virus de la «Lumpy skin disease », CILLI (12) le virus du fibrome de Shope et celui de la clavelée. HESS, MAY et PATTY (13) ont effectué sur ces mêmes celiules la culture d'un grand nombre de virus notamment ceux de la fièvre aphteuse, de la stomatite vésiculaire, de la «lumpy skin disease» et celui de la peste porcine africaine déjà passée sur cultures cellulaires. Nos résultats complètent donc ceux de ces auteurs et contribuent à montrer l'intérêt de ce nouveau type de cellules.

La faculté d'un virus de se multiplier sur certains types de cellules peut constituer un ensemble de caractères facilitant son identification et une étude détaillée de la multiplication de chaque virus sur des souches diverses de cellules est donc souhaitable. MADIN (8) a fait un travail méritore en dressant la liste, quoiqu'incomplète, des cellules supportant la multiplication des virus des animaux. Untableau d'ensemble concernant un plus grand nombre de cellules avec des détails sur leurs lésions respectives nous permettra la différenciation d'un certain nombre d'entre eux.

\section{SUMMARY}

\section{Culture of the Infectious bovine Rhinotracheitis on sheep embryo testicle cells.}

The multiplication of the Infectious bavine Rhinotracheitis has been obtained on embryo sheẹp tọsticlę cellș cultuvated in a medıum prepared with lactalbumin 
hydrolysat in Hanks' buffered saline solution, added of lamb and calf serum. The cylopathic effect was produced after a incubation of twenty to forty hours, at $370 \mathrm{C}$. Large eosinophilic inclusians of a particular lype were abserved in the cyloplasma of a few number of affected cells. The seroprotected cells remained normal.

\section{RESUMEN}

\section{Cultivo del virus de la rinotraqueitis infecciosa de los bovinos sobre las celulas testiculares del embrion de oveja}

La multiplicación del virus de la rinotraqueitıs infecciosa bovina puede efectuarse sabre células testiculares del embrión de oveja, cultivadas in vitro, en medio a base de hidralisado de lactoalbùmina con un agregado de suero de cordero o de ternero $\mathrm{Al}$ cabo de 20 à 40 horas de incubación a $37^{\circ}$ : C, ella se manıfiesta por un efecto citopatógeno. Se han abservado grandes inclusiones de eosinófilos de un tipo particular en el ciloplama de un cierto número de células lesionadas. Las células seroprotegidas permanecen normales.

\section{BIBLIOGRAPHIE}

1. PROVOST (A.) ef BORREDON (C.). Note sur la rhinotrachéite infectieuse bovine en Afrique centrale. Isolement du virus. Enquête sérologique. Rev. El. Méd. Vét. Poys tropicaux, 1964, 17, n² 2.

2. MADIN (S. H.), YORK (C. J.) et MC KERCHER (D. G.). - Isolation of the infectious rhinotracheitis virus. Science 1956, 124 : 721 722 .

3. SCHWARZ (A. J. F.), YORK (C. J.), ZIRBEL (L. W.) et ESTELA (L. A.). - Modification of infectious bovine rhinotrachetis (IBR) virus in tissue culture and development of a vaccine. Proc. Soc. Exptl. Biol. Med. 1957, $96:$ 453-58.

4. CABASSO (V. J.), BROWN (R. G.) et $\operatorname{COX}\left(H . R_{1}\right)$. - Infectious bovine rhinotracheitis (I. B. R.) I. Propagation of virus in cancer cells of human origin (Hela). Proc. Soc. Exptl. Biol. Med. 1957, 95 : 471-76.

5. ORSI (E. V.) et CABASSO (V. J.). - Infectious bovine rhinotracheitis (IBR). IV. Cytological changes in infected bovine kidney and Hela cultures. Proc. Soc. Exptl. Biol. (N. Y.) 1958, $98: 637-39$.

6. SCHWARZ (A. J. F.), ZIRBEL (L. W.), ESTELLA (L. A.) ef YORK (C. J.). - Propagation and modification of infectious bovine rhinotracheltis (I. B. R.) virus in porcine kidney tissue culture. Proc. Soc. Exptl. Biol. Med. 1958, 97: 680-83.

7. CHEATHAM (W. J.) et CRANDELL (R. A.). Occurence of intranuclear inclusions in tissue culture infected with virus of infectious bovine rhinotracheitls. Proc. Soc. Exptl. Biol. Med., 1957, $96:$ 536-38.

8. MADIN (S. H.). - Tissue culture in veterinary medical research. Adv. Vet. Sc., 1959, 5: 329-417.

9. MC KERCHER, - Infectlous bovine rhinotracheitis. Adv. Vet. Sc., 1959, $5: 299-328$.

10. KNOCKE (K. W.) et LIESS (B.). - Die morphologische Entwicklung des virus der rhinotracheitis infectiosa des Rindes. $Z b l$. Bakt. Abt. Orig., 1961, I8I : 429-39.

11. PRYDIE (J.) ef COACKLEY (W.). «Lumpy skin disease » Tissue culture studies. Bull. EpIz. Dis. Afric., 1959, 7 : 37-50.

12. CILLI (V.). - Le virus de fibrome de shope. Rec. Méd. Vét. Alfort, 1961, 137 : 569-588.

Sur quelques aspects biologiques du virus de la clavelée. Rec. Méd. Vét. Alfort., 1961, $137:$ : 663-78.

13. HESS (W. R.) et PATTY (R. E.). - Serial cultures of lamb testicular cells and their use in virus studies. Amer. J. Vef. Res., 1963. $24:$ :59-64. 